\title{
Comprehensive systematic review summary: Disease-modifying therapies for adults with multiple sclerosis
}

\author{
Report of the Guideline Development, Dissemination, and Implementation \\ Subcommittee of the American Academy of Neurology
}

\begin{abstract}
Alexander Rae-Grant, MD, Gregory S. Day, MD, MSc, Ruth Ann Marrie, MD, PhD, Alejandro Rabinstein, MD, Bruce A.C. Cree, MD, PhD, MAS, Gary S. Gronseth, MD, Michael Haboubi, DO, June Halper, MSN, APN-C, MSCN, Jonathan P. Hosey, MD, David E. Jones, MD, Robert Lisak, MD, Daniel Pelletier, MD, Sonja Potrebic, MD, PhD, Cynthia Sitcov, Rick Sommers, LMSW, Julie Stachowiak, PhD, Thomas S.D. Getchius, Shannon A. Merillat, MLIS, and Tamara Pringsheim, MD, MSc
\end{abstract}

Neurology ${ }^{\circledR}$ 2018;90:789-800. doi:10.1212/WNL.0000000000005345

\section{Abstract \\ Objective}

To review evidence on starting, switching, and stopping disease-modifying therapies (DMTs) for multiple sclerosis (MS) in clinically isolated syndrome (CIS), relapsing-remitting MS (RRMS), and progressive MS forms.

\section{Methods}

Relevant, peer-reviewed research articles, systematic reviews, and abstracts were identified (MEDLINE, CENTRAL, EMBASE searched from inception to November 2016). Studies were rated using the therapeutic classification scheme. Prior published Cochrane reviews were also used.

\section{Results}

Twenty Cochrane reviews and an additional 73 full-text articles were selected for data extraction through an updated systematic review (completed November 2016). For people with RRMS, many DMTs are superior to placebo (annualized relapses rates [ARRs], new disease activity [new MRI T2 lesion burden], and in-study disease progression) (see summary and full text publications). For people with RRMS who experienced a relapse on interferon- $\beta$ (IFN- $\beta$ ) or glatiramer acetate, alemtuzumab is more effective than IFN- $\beta$-1a $44 \mu \mathrm{g}$ subcutaneous 3 times per week in reducing the ARR. For people with primary progressive MS, ocrelizumab is probably more effective than placebo (in-study disease progression). DMTs for MS have varying adverse effects. In people with CIS, glatiramer acetate and IFN- $\beta$-1a subcutaneous 3 times per week are more effective than placebo in decreasing risk of conversion to MS. Cladribine, immunoglobulins, IFN- $\beta$-1a $30 \mu \mathrm{g}$ intramuscular weekly, IFN- $\beta$-1b subcutaneous alternate day, and teriflunomide are probably more effective than placebo in decreasing risk of conversion to MS. Suggestions for future research include studies considering comparative effectiveness, usefulness of high-efficacy treatment vs stepped-care protocols, and research into predictive biomarkers.

\author{
Correspondence \\ American Academy of \\ Neurology \\ guidelines@aan.com
}

\section{RELATED ARTICLES}

\section{Editorial}

Complexity of MS

management in the current treatment era

Page 761

\section{Article}

Practice guideline recommendations summary: Diseasemodifying therapies for adults with multiple sclerosis: Report of the Guideline Development, Dissemination, and Implementation Subcommittee of the American Academy of Neurology

Page 777

\footnotetext{
From the Department of Neurology (A.R.-G.), Cleveland Clinic, OH; Department of Neurology (G.S.D.), Charles F. and Joanne Knight Alzheimer Disease Research Center, Washington University in St. Louis, MO; Department of Community Health Sciences (R.A.M.), Max Rady College of Medicine, Rady Faculty of Health Sciences, University of Manitoba, Winnipeg, Canada; Department of Neurology (A.R.), Mayo Clinic, Rochester, MN; UCSF Weill Institute for Neurosciences, Department of Neurology (B.A.C.C.), University of California, San Francisco; Department of Neurology (G.S.G.), Kansas University Medical Center, Kansas City; Department of Neurology, School of Medicine (M.H.), University of Louisville, KY; Consortium of Multiple Sclerosis Centers (J.H.), Hackensack, NJ; Department of Neuroscience (J.P.H.), St. Luke's University Health Network, Bethlehem, PA; Department of Neurology (D.E.J.), University of Virginia, Charlottesville; Consortium of Multiple Sclerosis Centers (R.L.), Hackensack, NJ; Department of Neurology, School of Medicine (R.L.), Wayne State University, Detroit, MI; Department of Neurology, Keck School of Medicine (D.P.), University of Southern California, Los Angeles; Neurology Department (S.P.), Southern California Permanente Medical Group, Kaiser, Los Angeles; National Multiple Sclerosis Society (C.S.), Arlington, VA; National Multiple Sclerosis Society (R.S.), New York, NY; Santa Fe (I.S.), NM; Heart Rhythm Society (T.S.D.G.), Washington, DC; American Academy of Neurology (S.A.M.), Minneapolis, MN; and Department of Clinical Neurosciences, Psychiatry, Pediatrics and Community Health Sciences, Cumming School of Medicine (T.P.), University of Calgary, Alberta, Canada.
} 


\section{Glossary}

AAN = American Academy of Neurology; AE = adverse effect; ARR = annualized relapse rate; CIS = clinically isolated syndromes; DMT = disease-modifying therapy; EDSS = Expanded Disability Status Scale; HYP = high-yield process; IFN$\beta=$ interferon $-\beta ; \mathbf{I M}=$ intramuscular; $\mathbf{M S}=$ multiple sclerosis; PPMS = primary progressive multiple sclerosis; $\mathbf{R C T}=$ randomized controlled trial; RRMS = relapsing-remitting multiple sclerosis; SPMS = secondary progressive multiple sclerosis.

This article summarizes the findings and conclusions of an American Academy of Neurology (AAN) practice guideline on the efficacy and safety of disease-modifying therapies (DMTs) in multiple sclerosis (MS). References e1 through e49, cited here, are available at links.lww.com/WNL/A374 as a data supplement to this summary article.

A companion article presents the recommendations and suggestions for future research. ${ }^{1}$ The complete practice guideline (systematic review, recommendations, and suggestions for future research) is available at links.lww.com/WNL/ A429 as a data supplement to the companion recommendations article. This guideline, although not a formal update to the 2002 AAN guideline on DMTs, ${ }^{2}$ replaces that earlier guideline. The complete guideline includes full details of the methodology used, including risk of bias classification for each study, confidence in the evidence determinations, and rationales for recommendation strength; space restrictions precluded more detailed description in this article.

MS affects more than 400,000 people in the United States and more than 2.3 million people worldwide. ${ }^{3}$ Since 1993, DMTs have been approved in the United States for treating relapsing forms of MS; most of these therapies are approved for use in other countries. Many additional medications have been used off-label for MS disease modification.

Multiple new DMTs have become available since publication of the 2002 AAN practice guideline on DMTs in MS. ${ }^{2}$ Clinicians and people with MS may now choose from several medications, with differing mechanisms of action, risk profiles, and monitoring requirements. Before recommending a specific therapy, the clinician must navigate these complexities while carefully balancing the potential for therapeutic benefits of a medication with patient preferences, monitoring recommendations, drugand individual-specific risk factors, and concerns regarding the long-term risk of MS-related disability and morbidity.

The new practice guideline, ${ }^{1}$ based on the systematic review summarized here, provides guidance concerning current issues surrounding DMT for MS prescribing, specifically addressing

\section{$\oplus$ Supplemental Data}

Practice Guidelines

NPub.org/77nyxt the following questions pertinent to clinically isolated syndromes of demyelination (CIS), relapsing-remitting MS (RRMS), and progressive forms of MS (secondary progressive MS [SPMS] and primary progressive MS [PPMS]):

1. In people with RRMS, are DMTs superior to placebo or other DMTs as measured by annualized relapse rates (ARRs) and the relative risk of relapse at 2 years?

2. In people with RRMS, are DMTs superior to placebo or other DMTs in reducing MRI-detected new disease activity as measured by new T2 lesion burden or atrophy measures?

3. In people with RRMS, are DMTs superior to placebo or other DMTs in preventing disease progression as measured by in-study disease progression measures?

4. In people with RRMS who experience disease activity while on a DMT, is changing to a different DMT superior to continuing the present DMT in terms of relapse rate and MRI-detected T2 or gadolinium-enhanced lesion activity?

5. In people with progressive MS, are DMTs superior to placebo or other DMTs as measured by relapse rate or instudy disease progression?

6. What are the adverse effects (AEs) of DMTs in people with MS compared with placebo (AE-related discontinuation and serious or life-threatening AEs)?

7. In people with CIS, are DMTs superior to placebo in decreasing the risk of conversion to MS?

\section{Description of the analytic process}

In May 2015, the AAN guideline subcommittee recruited a multidisciplinary panel to develop the guideline on which this systematic review is based. The panel consists of $12 \mathrm{AAN}$ physician and nurse members, 2 representatives from the Consortium of Multiple Sclerosis Centers, and 3 patient representatives. Two AAN staff representatives were also appointed to the panel. Conflicts of interest were reviewed by the panel leadership; panelists with conflicts did not participate in systematic review development.

The practice guideline follows the methodologies described in the 2011 edition of the AAN's guideline development process manual, as amended to include an updated classification scheme for therapeutic studies, a formalized prioritization process for guideline topic nominations, and a change in the order of steps for the external (peer) review process. ${ }^{4}$ Institute of Medicine standards for systematic review and clinical practice guideline development were adhered to throughout the 
development process, including posting of the protocol and draft document with recommendations for public review and active solicitation of patient input. ${ }^{5,6}$ For the systematic review, the panel used appropriate Cochrane reviews (assessed by 2 panelists working independently of each other and using A Measurement Tool to Assess Systematic Reviews quality) ${ }^{7}$ in addition to treatment-specific systematic reviews. Two nonconflicted panelists working independently reviewed abstracts for article inclusion. From their review, full-text articles were obtained for data extraction, and risk of bias was established by 2 panelists rating articles independently of each other. Data extraction was performed by the AAN staff guideline methodologist and confirmed by panel members. The panel considered data for efficacy outcomes from randomized controlled trials (RCTs). For harms, the panel considered data from RCTs, cohort studies, case reports, and case series. Metaanalyses were performed when appropriate. Before data analysis, the panel completed an anonymous survey to establish the minimal clinically meaningful difference for measures of DMT efficacy and AEs; this information was used in the analytic portion of the guideline. Conclusions were developed using a modified Grading of Recommendations, Assessment, Development and Evaluation process. ${ }^{8}$

\section{Analysis of evidence}

Twenty Cochrane systematic reviews were identified and used in the evidence review process. These systematic reviews included data from 70 RCTs, which were included in the panel's evidence synthesis. For the update of the Cochrane reviews and de novo systematic review (completed November 2016), the combined searches yielded 4,301 abstracts. Each abstract was reviewed for relevance by at least 2 panel members, who deemed 284 as relevant. The corresponding articles were obtained for full-text review by 2 panelists working independently of each other. An additional 73 articles were identified for data extraction.

All trials included individuals with MS aged 18 years or older. The maximum age of participants varied across trials but was usually between 50 and 60 years. Most studies were 2 years in length (range 6 months-3 years). Trials occurred in multiple countries worldwide. Twenty-three DMTs were systematically reviewed: methotrexate, cyclophosphamide, pulsed corticosteroids for disease modification, interferon- $\beta$ (IFN- $\beta$ ) (4 types: IFN- $\beta-1 b$ subcutaneous alternate day, IFN- $\beta-1 \mathrm{a}$ intramuscular [IM] subcutaneous, pegylated IFN subcutaneous every other week, IFN- $\beta$-1a subcutaneous 3 times per week), glatiramer acetate (3 types: proprietary daily 20-mg subcutaneous form, proprietary 3-day-per-week 40-mg subcutaneous form, generic 20-mg subcutaneous daily form), natalizumab, azathioprine, teriflunomide, mycophenolate mofetil, rituximab, ocrelizumab, daclizumab, mitoxantrone, alemtuzumab, fingolimod, dimethyl fumarate, IV immunoglobulin for disease modification, and cladribine.

Safety note: After US Food and Drug Administration (FDA) approval was received, daclizumab (ZINBRYTA) was voluntarily removed from the market on March 2, 2018, by its manufacturers, Biogen and AbbVie, due to serious adverse events in relapsing $\mathrm{MS} .^{8 \mathrm{a}}$

The results of the systematic review support the following evidence-based conclusions. All recommendations are provided in the companion publication. ${ }^{1}$

\section{In people with RRMS, are DMTs superior to placebo or other DMTs as measured by ARRs and the relative risk of relapse at 2 years?}

For this question, figure 1 presents the data regarding ARRs, and figure 2 presents the data on the relative risk of relapse at 2 years. The table shows the findings and conclusions for both the ARRs and the relative risk of relapse at 2 years.

\section{In people with RRMS, are DMTs superior to placebo or other DMTs in reducing MRI new disease activity as measured by new T2 lesion burden or atrophy measures?}

\section{Risk of new or enlarging T2 lesions}

The following DMTs are more effective than placebo in reducing the risk of MRI-detected new or enlarging T2 lesions (high confidence): fingolimod, ${ }^{9,10}$ IFN- $\beta-1 \mathrm{a} 44 \mu \mathrm{g}$ subcutaneous 3 times weekly, ${ }^{11}$ and natalizumab. ${ }^{12}$

Ocrelizumab ${ }^{13}$ is more effective than IFN- $\beta$-1a subcutaneous 3 times per week in reducing the risk of new or enlarging T2 lesions detected by MRI (high confidence).

Cladribine ${ }^{14}$ is probably more effective than placebo in reducing the risk of new or enlarging $\mathrm{T} 2$ lesions detected by MRI (moderate confidence).

The following DMTs are probably more effective than other DMTs in reducing the risk of MRI-detected new or enlarging T2 lesions (moderate confidence): alemtuzumab (vs IFN$\beta$-1a subcutaneous 3 times per week), ${ }^{15}$ fingolimod (vs IFN$\beta$-1a IM once weekly), ${ }^{16}$ IFN- $\beta$-1a $44 \mu$ g subcutaneous 3 times weekly (vs IFN- $\beta$-1a IM once weekly). ${ }^{17}$

IFN- $\beta$ - 1 a subcutaneous 3 times per week is possibly no more effective than glatiramer acetate in decreasing the risk of MRIdetected new or enlarging T2 lesions (low confidence). ${ }^{18}$

There is insufficient evidence to determine the efficacy of azathioprine compared with IFN- $\beta^{19}$ in reducing the risk of MRIdetected new or enlarging T2 lesions (very low confidence).

\section{Reducing the volume or number of T2 lesions}

The following DMTs are more effective than placebo in reducing the volume or number of MRI-detected T2 lesions (high confidence): daclizumab high-yield process (HYP), ${ }^{20}$ dimethyl fumarate, ${ }^{18,21}$ glatiramer acetate, ${ }^{18}$ IFN- $\beta$-1a $30 \mu \mathrm{g}$ IM weekly, ${ }^{22}$ mitoxantrone, ${ }^{23}$ natalizumab, ${ }^{12}$ and pegylated IFN. ${ }^{24}$ See the safety note on this page. ${ }^{8 a}$ 
Figure 1 Outcome: Annualized relapse rate, relapsing-remitting multiple sclerosis

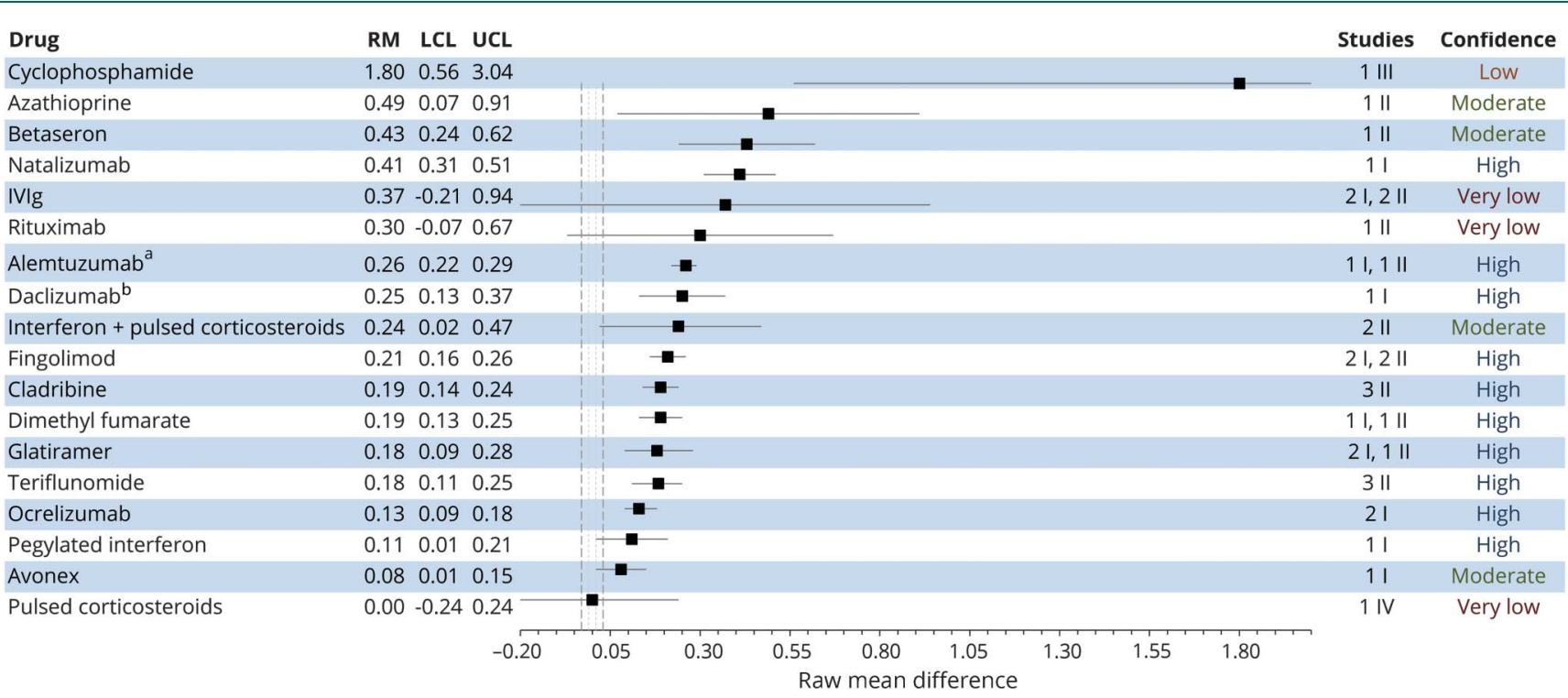

IVIg = IV immunoglobulin; $L C L=$ lower confidence limit; $R M=$ raw mean difference; $U C L=$ upper confidence limit. ${ }^{a}$ Versus interferon- $\beta-1$ a $44 \mu \mathrm{g} 3$ times per week subcutaneously. ${ }^{b}$ See safety note on page $791 .{ }^{8 a}$

Rituximab $^{25}$ and teriflunomide ${ }^{26}$ are probably more effective than placebo in reducing the volume or number of MRIdetected $\mathrm{T} 2$ lesions (moderate confidence).
The following DMTs are probably more effective than other DMTs in reducing the volume or number of MRIdetected T2 lesions (moderate confidence): alemtuzumab

Figure 2 Outcome: Relative risk of relapse at 2 years, relapsing-remitting multiple sclerosis

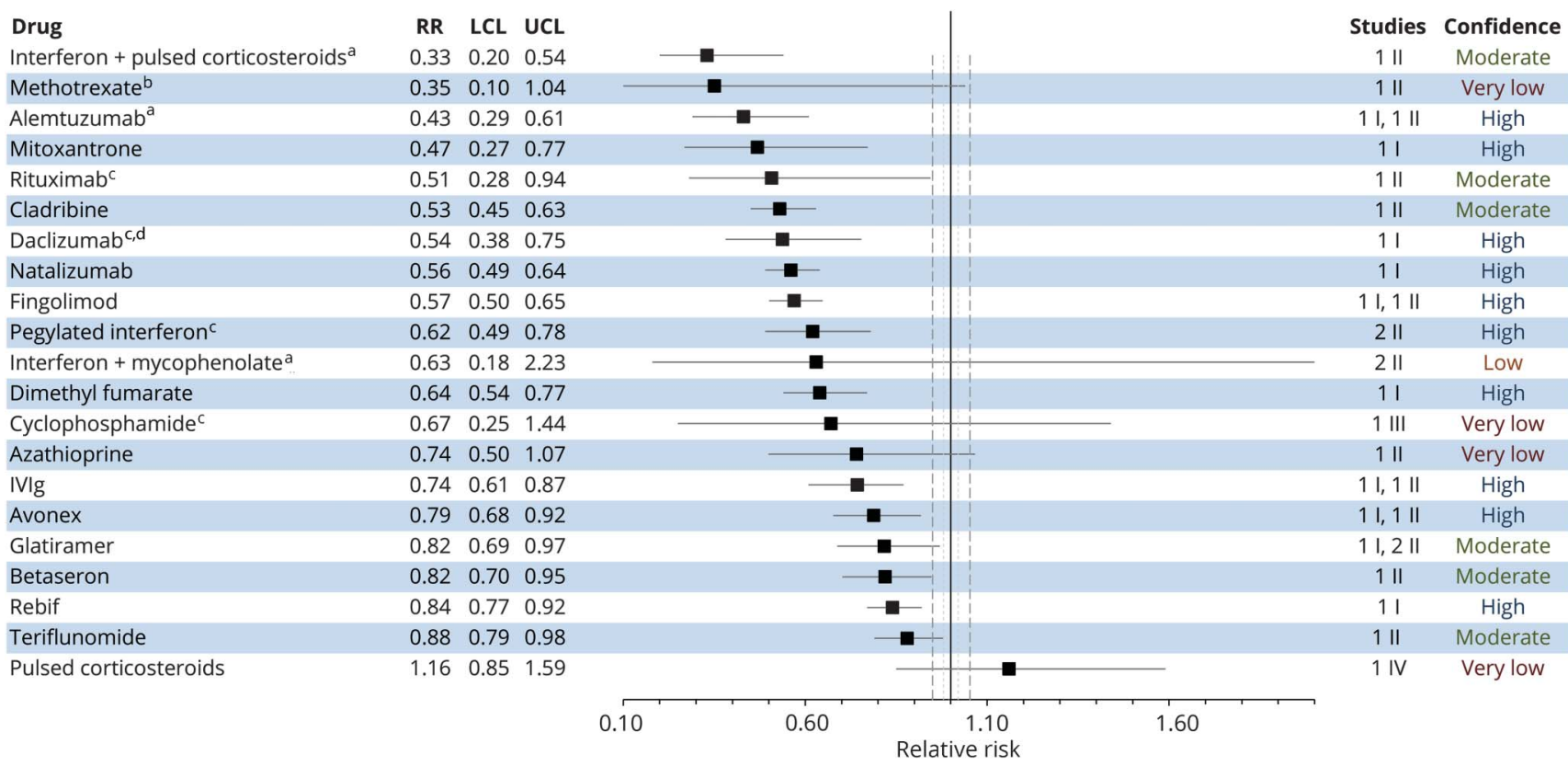

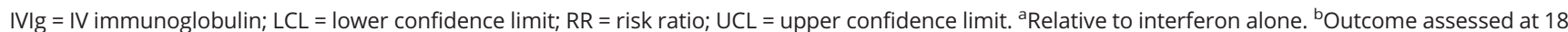
months. 'Outcome assessed at 1 year. ${ }^{\mathrm{d}}$ See safety note on page $791 .{ }^{8 a}$ 
Table Efficacy of disease-modifying therapies (DMTs) for reducing the annualized relapse rate (ARR) and risk of relapse at 2 years

\begin{tabular}{|c|c|c|c|c|}
\hline \multirow[b]{2}{*}{$\begin{array}{l}\text { Confidence } \\
\text { strength }\end{array}$} & \multicolumn{2}{|l|}{ Reduction of the ARR } & \multicolumn{2}{|c|}{ Reduction of risk of relapse at $2 y$} \\
\hline & $\begin{array}{l}\text { Compared with } \\
\text { placebo }\end{array}$ & $\begin{array}{l}\text { Compared with other } \\
\text { DMTs }\end{array}$ & Compared with placebo & Compared with other DMTs \\
\hline \multirow[t]{9}{*}{ High } & $\begin{array}{l}\text { Cladribine }{ }^{14, e 34} \text { more } \\
\text { effective }\end{array}$ & $\begin{array}{l}\text { Alemtuzumab more } \\
\text { effective than IFN- } \beta \text {-1a } \\
\text { subcutaneous } 3 \text { times per } \\
\text { wk }^{15,29}\end{array}$ & $\begin{array}{l}\text { Daclizumab HYPa more } \\
\text { effective (outcome measured } \\
\text { at } 1 \mathrm{y})^{20}\end{array}$ & $\begin{array}{l}\text { Alemtuzumab }{ }^{15,29} \text { more effective than IFN- } \\
\beta-1 \text { a subcutaneous } 3 \text { times per wk }\end{array}$ \\
\hline & $\begin{array}{l}\text { Daclizumab HYPa more } \\
\text { effective }^{20}\end{array}$ & $\begin{array}{l}\text { Azathioprine more } \\
\text { effective than } \\
\beta \text {-interferons } \\
{ }^{19, e 35}\end{array}$ & $\begin{array}{l}\text { Dimethyl fumarate }{ }^{18,21} \text { more } \\
\text { effective }\end{array}$ & - \\
\hline & $\begin{array}{l}\text { Dimethyl fumarate }{ }^{18,21} \\
\text { more effective }^{\mathrm{b}}\end{array}$ & $\begin{array}{l}\text { Fingolimod more effective } \\
\text { than IFN- } \beta \text {-1a IM once per } \\
w^{16}\end{array}$ & Fingolimod ${ }^{9,10}$ more effective & - \\
\hline & $\begin{array}{l}\text { Fingolimod }{ }^{9,10, e 36} \text { more } \\
\text { effective }\end{array}$ & $\begin{array}{l}\text { Ocrelizumab more } \\
\text { effective than IFN- } \beta \text { - } 1 \text { a } \\
\text { subcutaneous } 3 \text { times per } \\
\text { wk }^{13}\end{array}$ & $\begin{array}{l}\text { Immunoglobulins }{ }^{39,40} \text { more } \\
\text { effective }\end{array}$ & - \\
\hline & $\begin{array}{l}\text { Glatiramer acetate }{ }^{18,34,} \\
\text { e37 more effective }\end{array}$ & - & $\begin{array}{l}\text { IFN- } \beta \text { - } 1 \text { a IM once per } w k^{22,32} \\
\text { more effective }\end{array}$ & - \\
\hline & $\begin{array}{l}\text { Natalizumab }{ }^{12} \text { more } \\
\text { effective }\end{array}$ & - & $\begin{array}{l}\text { IFN- } \beta \text {-1 a subcutaneous } 3 \\
\text { times per } w^{11} \text { more effective }\end{array}$ & - \\
\hline & $\begin{array}{l}\text { Pegylated IFN }{ }^{24} \text { more } \\
\text { effective }\end{array}$ & - & $\begin{array}{l}\text { Mitoxantrone } e^{23} \text { more } \\
\text { effective }\end{array}$ & - \\
\hline & $\begin{array}{l}\text { Teriflunomide } 26, \mathrm{e} 38, \mathrm{e} 39 \\
\text { more effective }\end{array}$ & - & Natalizumab ${ }^{12}$ more effective & - \\
\hline & - & - & $\begin{array}{l}\text { Pegylated IFN more effective } \\
\text { (outcome measured at } 1 \text { y) })^{24}\end{array}$ & - \\
\hline \multirow[t]{6}{*}{ Moderate } & $\begin{array}{l}\text { Azathioprine probably } \\
\text { more effective }{ }^{\mathrm{e} 40}\end{array}$ & - & $\begin{array}{l}\text { Cladribine probably more } \\
\text { effective }^{14}\end{array}$ & $\begin{array}{l}\text { Daclizumab HYPa probably more effective } \\
\text { than IFN- } \beta-1 \text { a IM once per wk (outcome } \\
\text { measured at } 3 \text { y) })^{27}\end{array}$ \\
\hline & $\begin{array}{l}\text { IFN- } \beta \text {-1a IM once per } \\
\text { wk } 22 \text { probably more } \\
\text { effective }\end{array}$ & - & $\begin{array}{l}\text { Glatiramer acetate probably } \\
\text { more effective }{ }^{18,34,35}\end{array}$ & \\
\hline & $\begin{array}{l}\text { IFN- } \beta-1 \mathrm{~b} \text { subcutaneous } \\
\text { alternate day }{ }^{\mathrm{e}} \text { probably } \\
\text { more effective }\end{array}$ & - & $\begin{array}{l}\text { IFN- } \beta \text { - } 1 \text { b subcutaneous } \\
\text { alternate day probably more } \\
\text { effective } \mathrm{e}^{\mathrm{e}}\end{array}$ & - \\
\hline & $\begin{array}{l}\text { Pulsed corticosteroids } \\
\text { added to IFN- } \beta-1 a^{36, \mathrm{e} 41} \\
\text { probably more effective }\end{array}$ & - & $\begin{array}{l}\text { Pulsed corticosteroids added } \\
\text { to IFN- } \beta-1 a^{\text {e41 }} \text { probably more } \\
\text { effective }\end{array}$ & - \\
\hline & - & $\begin{array}{l}\text { Daclizumab HYP }{ }^{27} \text { IFN- } \beta-1 a \\
\text { once per wk probably more } \\
\text { effective }^{a}\end{array}$ & $\begin{array}{l}\text { Rituximab probably more } \\
\text { effective (outcome measured } \\
\text { at } 1 \text { y) })^{25}\end{array}$ & - \\
\hline & - & - & $\begin{array}{l}\text { Teriflunomide }{ }^{26} \text { probably } \\
\text { more effective }\end{array}$ & - \\
\hline \multirow[t]{4}{*}{ Low } & $\begin{array}{l}\text { Cyclophosphamide }{ }^{\mathrm{e} 42} \\
\text { possibly more effective }\end{array}$ & - & - & $\begin{array}{l}\text { Mycophenolate mofetil plus IFN- } \beta \text { - } 1 \text { a IM } \\
\text { weekly }{ }^{31, \text { e43 }} \text { possibly no more effective than } \\
\text { IFN plus placebo (outcome measured at } 1 \mathrm{y} \text { ) }\end{array}$ \\
\hline & - & - & - & $\begin{array}{l}\text { Complex nonbiologic generic glatiramer } \\
\text { acetate (Glatopa) })^{\mathrm{e} 4} \text { possibly no more } \\
\text { effective than glatiramer acetate (Copaxone) }\end{array}$ \\
\hline & - & - & - & $\begin{array}{l}\text { IFN- } \beta-1 \text { a IM once weekly }{ }^{37} \text { possibly no more } \\
\text { effective than glatiramer acetate (Copaxone) }\end{array}$ \\
\hline & - & - & - & $\begin{array}{l}\text { IFN- } \beta-1 \text { a subcutaneous } 3 \text { times weekly }{ }^{\mathrm{e} 45} \\
\text { possibly no more effective than glatiramer } \\
\text { acetate (Copaxone) }\end{array}$ \\
\hline
\end{tabular}


Table Efficacy of disease-modifying therapies (DMTs) for reducing the annualized relapse rate (ARR) and risk of relapse at 2 years (continued)

\begin{tabular}{|c|c|c|c|c|}
\hline \multirow[b]{2}{*}{$\begin{array}{l}\text { Confidence } \\
\text { strength }\end{array}$} & \multicolumn{2}{|l|}{ Reduction of the ARR } & \multicolumn{2}{|c|}{ Reduction of risk of relapse at $2 y$} \\
\hline & $\begin{array}{l}\text { Compared with } \\
\text { placebo }\end{array}$ & $\begin{array}{l}\text { Compared with other } \\
\text { DMTs }\end{array}$ & Compared with placebo & Compared with other DMTs \\
\hline & - & - & - & $\begin{array}{l}\text { IFN- } \beta \text { - } 1 \text { b subcutaneous alternate day }{ }^{\mathrm{e} 46, e 47} \\
\text { possibly no more effective than glatiramer } \\
\text { acetate (Copaxone) }\end{array}$ \\
\hline \multirow[t]{4}{*}{ Very low } & $\begin{array}{l}\text { Azathioprine insufficient } \\
\text { to support or refute } \mathrm{e}^{\mathrm{e} 0}\end{array}$ & - & $\begin{array}{l}\text { Azathioprine insufficient to } \\
\text { support or refute } e^{\text {e40 }}\end{array}$ & - \\
\hline & $\begin{array}{l}\text { Immunoglobulins } \\
\text { insufficient to support or } \\
\text { refute }^{39,40, e 48, e 49}\end{array}$ & - & $\begin{array}{l}\text { Cyclophosphamide } \\
\text { insufficient to support or } \\
\text { refute (outcome measured at } \\
12 \mathrm{mo})^{\mathrm{e} 42}\end{array}$ & - \\
\hline & $\begin{array}{l}\text { Pulsed corticosteroids } \\
\text { insufficient to support or } \\
\text { refute }^{30}\end{array}$ & - & $\begin{array}{l}\text { Methotrexate insufficient to } \\
\text { support or refute } \mathrm{e}^{\mathrm{2}}\end{array}$ & - \\
\hline & $\begin{array}{l}\text { Rituximab insufficient to } \\
\text { support or refute }^{25}\end{array}$ & - & $\begin{array}{l}\text { Pulsed corticosteroids } \\
\text { insufficient to support or } \\
\text { refute }^{30}\end{array}$ & - \\
\hline
\end{tabular}

Abbreviations: HYP = high-yield process; IFN- $\beta=$ interferon- $\beta$; IM = intramuscular.

a See safety note on page 791 . $^{8}$

${ }^{\mathrm{b}}$ Glatiramer acetate included as a reference comparator in a dimethyl fumarate study and not powered for study of noninferiority or superiority; required by regulatory agency.

(vs IFN- $\beta$ - 1 a subcutaneous 3 times per week) ${ }^{15}$ and daclizumab (vs IFN- $\beta$-1a IM once weekly). ${ }^{27}$ See safety note on page $791 .^{8 a}$

There is insufficient evidence to determine the efficacy of mycophenolate mofetil vs IFN- $\beta$-1a once weekly for reducing the volume or number of MRI-detected T2 lesions (very low confidence). ${ }^{28}$

There is insufficient evidence to determine the efficacy of pulsed corticosteroids $^{29}$ relative to placebo for reducing the volume or number of MRI-detected T2 lesions (very low confidence).

\section{Reducing loss of parenchymal volume}

Ocrelizumab $^{13}$ is more effective than IFN- $\beta$-1a $44 \mu \mathrm{g}$ subcutaneous 3 times weekly in reducing loss of parenchymal volume (high confidence).

Alemtuzumab is probably more effective than IFN- $\beta$ - 1 a $44 \mu \mathrm{g}$ subcutaneous 3 times weekly ${ }^{29}$ in reducing loss of parenchymal volume (moderate confidence).

Pulsed corticosteroids ${ }^{30}$ are probably more effective than placebo in reducing loss of parenchymal volume (moderate confidence).

There is insufficient evidence to determine the efficacy of the following DMTs relative to placebo in reducing loss of parenchymal volume (very low confidence): IFN- $\beta$-1a $30 \mu \mathrm{g}$ IM weekly ${ }^{22}$ and mycophenolate mofetil added to IFN- $\beta$-1a $30 \mu \mathrm{g}$ IM weekly. ${ }^{31}$

\section{In people with RRMS, are DMTs superior to placebo or other DMTs in preventing disease progression as measured by in-study disease progression measures?}

The most consistently reported measure for in-study disability progression was the proportion of people with MS with disability progression. Disability progression was defined by an increase in the Expanded Disability Status Scale (EDSS) of 1 point in those with a baseline EDSS score of 5.0 or lower, or an increase of 0.5 point in those with a baseline EDSS score of 5.5 or higher, sustained for 3 or 6 months, and detected over a 2-year study period (figure 3).

The following DMTs are more effective than placebo in reducing the risk of disability progression in people with RRMS (high confidence): daclizumab $\mathrm{HYP}^{20}$ dimethyl fumarate, ${ }^{18,21}$ fingolimod, ${ }^{9,10}$ IFN- $\beta$-1a $30 \mu \mathrm{g}$ IM weekly, ${ }^{22,32}$ IFN- $\beta$-1a $44 \mu \mathrm{g}$ subcutaneous 3 times weekly, ${ }^{11}$ mitoxantrone, ${ }^{23}$ natalizumab, ${ }^{12}$ pegylated IFN, $^{24}$ and teriflunomide. ${ }^{26,33}$ See safety note on page $791 .^{8 a}$

The following DMTs are more effective than other DMTs in reducing the risk of disability progression in people with RRMS (high confidence): alemtuzumab (vs IFN- $\beta$-1a $44 \mu \mathrm{g}$ subcutaneous 3 times weekly) ${ }^{15,29}$ and ocrelizumab (vs IFN$\beta$-1a $44 \mu \mathrm{g}$ subcutaneous 3 times weekly). ${ }^{13}$

Cladribine ${ }^{14}$ is probably more effective than placebo in reducing the risk of disability progression in people with RRMS (moderate confidence). 
Figure 3 Outcome: Relative risk (RR) of in-study disability progression at 2 years, relapsing-remitting multiple sclerosis

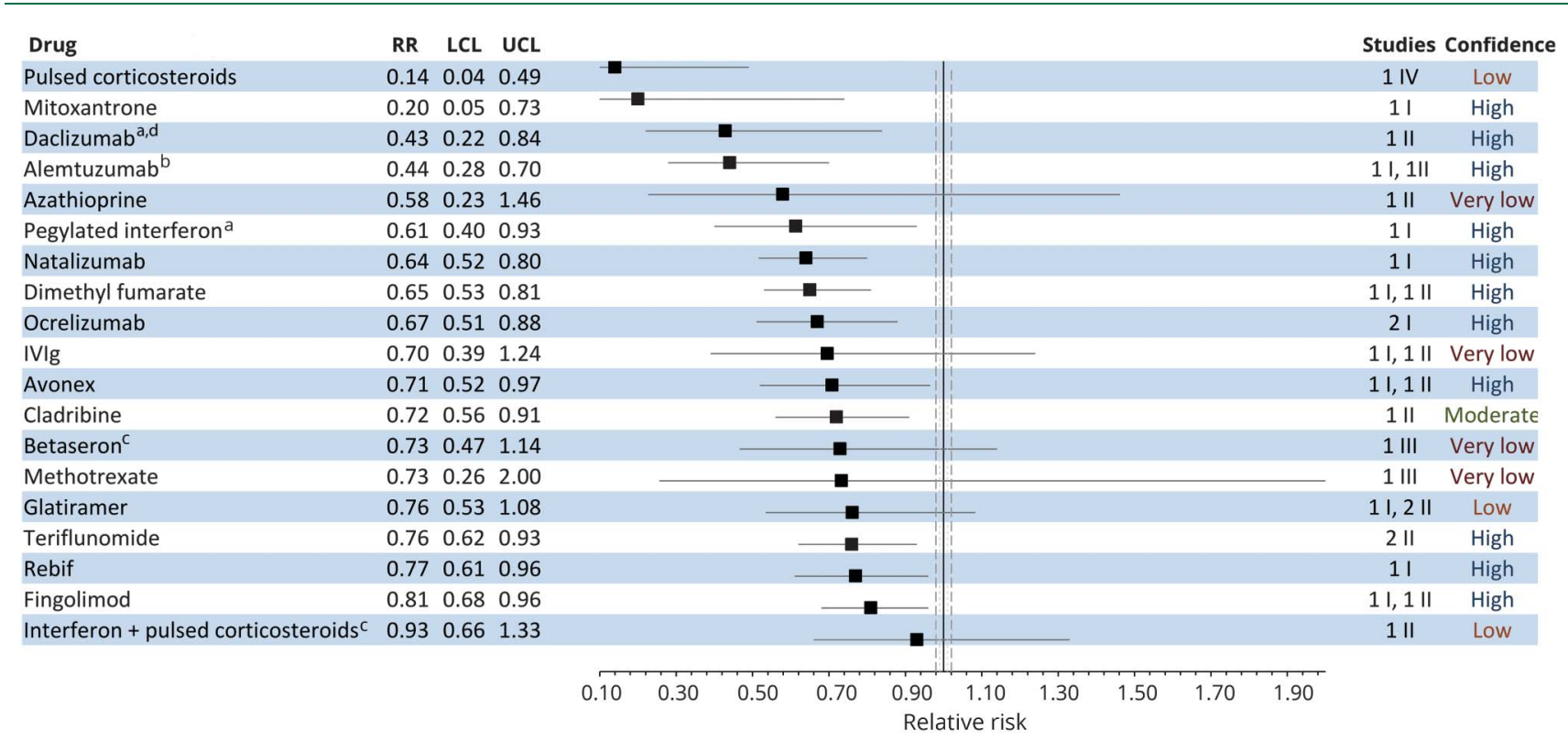

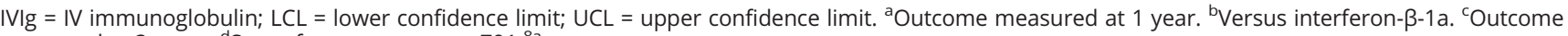
measured at 3 years. ${ }^{d}$ See safety note on page $791.8 a$

Daclizumab is probably more effective than IFN- $\beta$-1a $30 \mu \mathrm{g}$ $\mathrm{IM}^{27}$ in reducing the risk of disability progression in people with RRMS (moderate confidence). See safety note on page $791 .^{8 a}$

Pulsed corticosteroids ${ }^{30}$ are possibly more effective than placebo in reducing the risk of disability progression in people with RRMS (low confidence).

The following DMTs are possibly no more effective than placebo in reducing the risk of disability progression in people with RRMS (low confidence): glatiramer acetate 18,34,35 $^{\text {and }}$ pulsed corticosteroids added to IFN- $\beta$-1a IM once weekly. ${ }^{36}$

Fingolimod is possibly no more effective than IFN- $\beta$-1a IM weekly in reducing the risk of disability progression over 1 year (low confidence). ${ }^{16}$ See safety note on page $791 .^{8 a}$

IFN- $\beta$ - 1 a is possibly no more effective than glatiramer acetate in reducing the risk of disability progression over 3 years (low confidence). ${ }^{37}$

There is insufficient evidence to determine the efficacy of the following DMTs compared with placebo in reducing the risk of disability progression in people with RRMS (very low confidence): azathioprine, ${ }^{38}$ immunoglobulins, ${ }^{39,40}$ IFN- $\beta-1 b$ subcutaneous alternate day, ${ }^{\mathrm{e} 1}$ and methotrexate. ${ }^{\mathrm{e} 2}$

IFN- $\beta$ - $1 b$ alternate day is probably less effective than glatiramer acetate in reducing the risk of disability progression over 2 years (moderate confidence). ${ }^{\mathrm{e}}$

\section{In people with RRMS who experience disease activity while on a DMT, is changing to a different DMT superior to continuing the present DMT in terms of relapse rate and MRI- detected $\mathrm{T} 2$ or gadolinium-enhanced lesion activity?}

For individuals with RRMS who experienced a relapse on IFN- $\beta$ or glatiramer acetate, alemtuzumab is more effective than IFN- $\beta$-1a $44 \mu \mathrm{g}$ subcutaneous 3 times per week in reducing the ARR, the relapse risk, disability progression, and risk of new or enlarging T2 lesions over 2 years (high confidence). ${ }^{15}$

In individuals with RRMS who experience 1 or more relapses in the preceding 12 months on IFN- $\beta$, adding natalizumab is more effective than adding placebo in decreasing the risk of relapse over 2 years, the ARR, the risk of disability progression over 2 years, and the risk of new or enlarging T2 lesions at 1 year (high confidence). ${ }^{\mathrm{e}}$

In individuals with RRMS who experienced one or more relapses in the preceding 12 months on glatiramer acetate, there is insufficient evidence to determine the efficacy of natalizumab added to glatiramer acetate compared with placebo added to glatiramer acetate in decreasing the risk of relapse at 6 months (very low confidence). ${ }^{\mathrm{e} 4}$

Natalizumab added to glatiramer acetate is probably more effective than placebo added to glatiramer acetate in 
decreasing the cumulative number of new or enlarging $\mathrm{T} 2$ lesions at 6 months (moderate confidence). ${ }^{\text {4 }}$

Note that natalizumab is not presently approved/ recommended as an add-on therapy to other DMTs owing to potential safety concerns associated with combined use of this medication.

\section{In people with progressive MS, are DMTs superior to placebo or other DMTs as measured by relapse rate or in-study disease progression?}

\section{Risk of relapse}

Figure 4 presents these data regarding risk of relapse. IFN$\beta-1 b$ subcutaneous alternate day (SPMS) is more effective than placebo in reducing the risk of relapse in people with progressive MS (high confidence). ${ }^{\text {e5,e6 }}$

The following DMTs are probably more effective than placebo in reducing the risk of relapse in people with progressive MS (moderate confidence): IFN- $\beta$-1a $60 \mu \mathrm{g}$ IM weekly $(\text { SPMS) })^{\mathrm{e}}$ and mitoxantrone (worsening RRMS and SPMS). ${ }^{\text {e8 }}$

There is insufficient evidence to determine the efficacy of the following DMTs compared with placebo in reducing the risk of relapse in people with progressive MS (very low confidence): azathioprine, ${ }^{38}$ immunoglobulins, ${ }^{\text {e9,e10 }}$ and methotrexate (chronic progressive MS, older terminology that is undefined but included present PPMS and SPMS disease types). ${ }^{\text {e11 }}$ There is insufficient evidence to determine the efficacy of high-dose corticosteroids compared with low-dose corticosteroids $^{\mathrm{e} 12}$ in reducing the risk of relapse in people with SPMS (very low confidence).

\section{Disability progression}

The following DMTs are probably more effective than placebo in reducing the risk of in-study disability progression in people with progressive MS (RRMS or SPMS; moderate confidence): mitoxantrone (worsening RRMS and SPMS) e13 $^{13}$ and ocrelizumab (PPMS). ${ }^{\text {14 }}$
The following DMTs are possibly no more effective than placebo in reducing the risk of in-study disability progression in people with progressive MS (low confidence): cladribine (SPMS), ${ }^{\text {15 }}$ fingolimod (PPMS), ${ }^{\text {e16 }}$ glatiramer acetate (progressive forms of $\mathrm{MS}^{\mathrm{e}}{ }^{17}$ and PPMS ${ }^{\mathrm{e}}{ }^{18}$ ), IFN- $\beta$-1a $30 \mu \mathrm{g}$ IM weekly ( SPMS $^{\mathrm{e} 7}$ and PPMS ${ }^{\mathrm{e} 19}$ ), IFN- $\beta$-1a subcutaneous 3 times per week (SPMS), ${ }^{20}$ IFN- $\beta$-1b subcutaneous alternate day $\left(\mathrm{SPMS}^{\mathrm{e} 5, \mathrm{e} 6}\right.$ and PPMS ${ }^{\mathrm{e} 21}$ ), and rituximab (PPMS). ${ }^{\mathrm{e} 2}$

There is insufficient evidence to determine the efficacy of the following DMTs relative to placebo in reducing the risk of instudy disability progression in people with progressive MS (very low confidence): azathioprine, ${ }^{38}$ corticosteroids added to mitoxantrone, ${ }^{\text {e23 }}$ cyclophosphamide, ${ }^{\text {e24,e25 }}$ immunoglobulins, ${ }^{\mathrm{e} 9, \mathrm{e} 10}$ and methotrexate (CPMS [PPMS $\left.]\right)^{\mathrm{e}}{ }^{\mathrm{e} 1}$

There is insufficient evidence to determine the efficacy of high-dose corticosteroids relative to low-dose corticosteroids ${ }^{\mathrm{e} 26}$ in reducing the risk of in-study disability progression in people with progressive MS (very low confidence).

\section{What are the AEs of DMTs in people with MS compared with placebo (AE-related discontinuation and serious or life- threatening AEs)?}

A comprehensive review of adverse effects associated with DMTs is included in the full-text document (data supplement to the companion recommendations article, links.lww.com/ WNL/A429) and table.

\section{In people with CIS, are DMTs superior to placebo in decreasing the risk of conversion to MS?}

Figure 5 presents the data regarding risk of conversion to MS in people with CIS. For individuals with CIS, the following DMTs are more effective than placebo in reducing the proportion of individuals converting to MS (high confidence): glatiramer acetate ${ }^{\text {e27 }}$ and IFN- $\beta$-1a subcutaneous 3 times weekly. ${ }^{\text {e28 }}$

Figure 4 Outcome: Relative risk (RR) of relapse at 2 years secondary progressive multiple sclerosis

\begin{tabular}{|c|c|c|c|c|c|c|c|c|c|c|}
\hline Drug & $\mathbf{R R}$ & LCL & UCL & & & & & & Studies & Confidence \\
\hline Pulsed corticosteroids ${ }^{a}$ & 0.33 & 0.08 & 1.44 & & & i & & & $1 \|$ & Very low \\
\hline Azathioprine & 0.53 & 0.25 & 1.10 & & 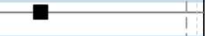 & $\frac{1}{1}$ & & & $1 \mathrm{II}$ & Very low \\
\hline Mitoxantrone & 0.68 & 0.48 & 0.94 & & $\square$ & 1 & & & $1 \mathrm{II}$ & Moderate \\
\hline Avonex & 0.72 & 0.54 & 0.95 & & $\square$ & 1 & & & 1 II & Moderate \\
\hline Betaseron $^{b}$ & 0.84 & 0.75 & 0.93 & & $\rightarrow$ & $\mid \begin{array}{l}1 \\
1 \\
1\end{array}$ & & & 2 II & High \\
\hline IVlg & 0.96 & 0.79 & 1.16 & & 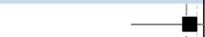 & 1 & & & $2 \|$ & Very low \\
\hline
\end{tabular}

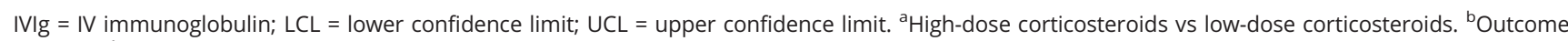
measured at 3 years. 
Figure 5 Outcome: Relative risk (RR) of conversion to multiple sclerosis over 2 years

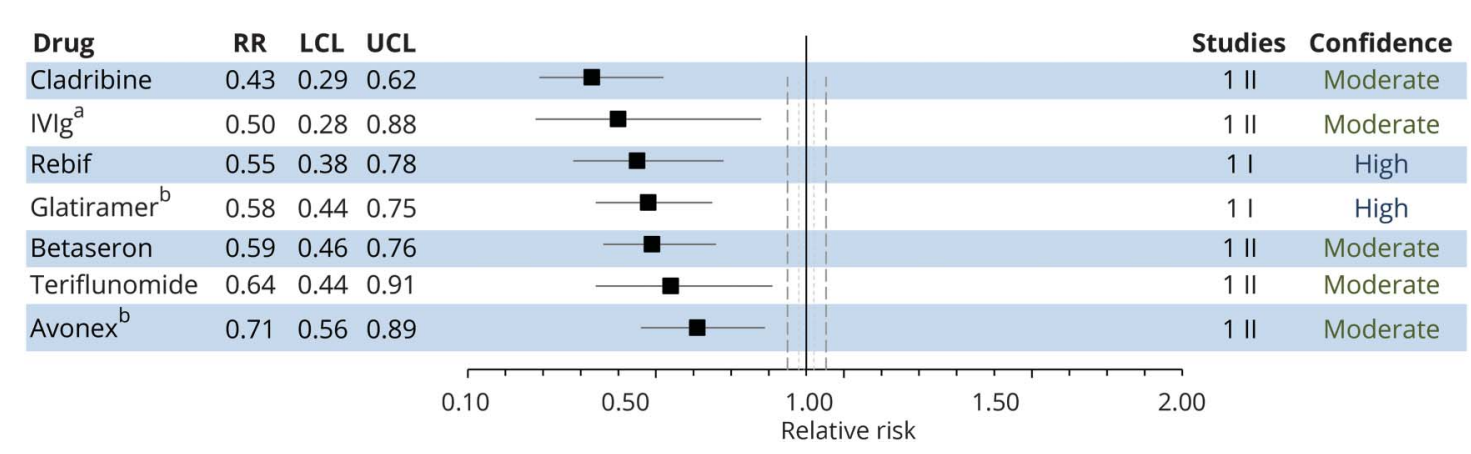

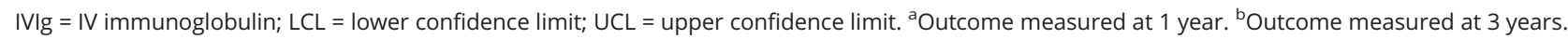

For individuals with CIS, the following DMTs are probably more effective than placebo in reducing the proportion of individuals converting to MS (moderate confidence): cladribine, ${ }^{\text {e29 }}$ immunoglobulins, ${ }^{\text {e30 }}$ IFN- $\beta$-1a $30 \mu \mathrm{g}$ IM weekly, ${ }^{\text {e31 }}$ IFN- $\beta-1 b$ subcutaneous alternate day, ${ }^{\text {e32 }}$ and teriflunomide. ${ }^{\mathrm{e} 3}$

\section{Discussion}

Multiple DMTs are now approved for use in CIS or MS, allowing people with MS and clinicians to consider DMT mechanism of action, efficacy, and AE profile in the decisionmaking process. This systematic review was used to develop a practice guideline for the use of DMT for MS, acknowledging the limits of current evidence. Measures of efficacy such as long-term disability, patient satisfaction, quality of life, and effects on MS symptoms may be important to the decision-making process but ultimately remain inadequately studied. Similarly, there is a dearth of high-quality evidence pertaining to the comparative efficacy of specific DMTs or various treatment strategies (e.g., high-efficacy treatment vs stepped-care treatment protocols). Future studies addressing these and other questions are needed to further inform treatment recommendations, particularly those pertaining to when to switch or stop DMTs.

\section{Author contributions}

Dr. Rae-Grant: study concept and design, acquisition of data, analysis or interpretation of data, drafting/revising the manuscript, critical revision of the manuscript for important intellectual content, study supervision. Dr. Day: study concept and design, analysis or interpretation of data, drafting/revising the manuscript, critical revision of the manuscript for important intellectual content. Dr. Marrie: study concept and design, acquisition of data, analysis or interpretation of data, drafting/revising the manuscript, critical revision of the manuscript for important intellectual content. Dr. Rabinstein: analysis or interpretation of data, drafting/revising the manuscript. Dr. Cree: study concept and design, drafting/revising the manuscript, critical revision of the manuscript for important intellectual content. Dr. Gronseth: analysis or interpretation of data, critical revision of the manuscript for important intellectual content, study supervision. Dr. Haboubi: study concept and design, analysis or interpretation of data, drafting/revising the manuscript. J. Halper: study concept and design, drafting/revising the manuscript, critical revision of the manuscript for important intellectual content. Dr. Hosey: critical revision of the manuscript for important intellectual content. Dr. Jones: study concept and design, drafting/revising the manuscript, critical revision of the manuscript for important intellectual content. Dr. Lisak: study concept and design, drafting/revising the manuscript, critical revision of the manuscript for important intellectual content. Dr. Pelletier: study concept and design, drafting/revising the manuscript, critical revision of the manuscript for important intellectual content. Dr. Potrebic: study concept and design, acquisition of data, analysis or interpretation of data, drafting/revising the manuscript, critical revision of the manuscript for important intellectual content, study supervision. C. Sitcov: study concept and design, drafting/revising the manuscript, critical revision of the manuscript for important intellectual content. R. Sommers: drafting/revising the manuscript, critical revision of the manuscript for important intellectual content. Dr. Stachowiak: study concept and design, drafting/revising the manuscript, critical revision of the manuscript for important intellectual content. T.S.D. Getchius: study supervision. S.A. Merillat: drafting/revising the manuscript, study supervision. Dr. Pringsheim: study concept and design, acquisition of data, analysis or interpretation of data, drafting/revising the manuscript, critical revision of the manuscript for important intellectual content, study supervision.

\section{Acknowledgment}

The authors thank the North American Research Committee on Multiple Sclerosis (NARCOMS) Registry for its assistance in administering an outcomes survey, the results of which were included in this practice guideline. NARCOMS is supported in part by the Consortium of Multiple Sclerosis Centers (CMSC) and the Foundation of the CMSC. 


\section{Study funding}

This practice guideline was developed with financial support from the American Academy of Neurology (AAN). Authors who serve as AAN subcommittee members or as methodologists (A.R.-G., G.S.D., A.R., G.S.G., M.H., S.P., T.P.), or who are or were AAN staff members (T.S.D.G., S.A.M.), were reimbursed by the AAN for expenses related to travel to subcommittee meetings where drafts of manuscripts were reviewed. All authors on the panel were reimbursed by the AAN for expenses related to travel to 2 in-person meetings.

\section{Disclosure}

A. Rae-Grant receives royalties from 2 textbooks he has published, 1 on neurology and 1 on multiple sclerosis (MS); organizes and receives honoraria for grand rounds and neurology review courses; and is local primary investigator for a clinical trial with MedDay Pharmaceuticals, for which he receives no personal compensation. A. Rabinstein reports no disclosures relevant to the manuscript. B. Cree has received compensation for consulting from AbbVie, Biogen, EMD Serono, GeNeuro, Genzyme/Sanofi Aventis, Novartis, and Shire; has given expert testimony and prepared an affidavit for medical malpractice cases ( 1 or 2 per year) within his area of expertise; and has acted as consultant in a legal proceeding for Acorda and Biogen. G. Gronseth serves as associate editor (level of evidence review) for Neurology ${ }^{\circledR}$; serves on the editorial advisory board for Neurology Now; and is compensated by the American Academy of Neurology (AAN) for methodologic activities. G. Day holds stock in ANI Pharmaceuticals. M. Haboubi has received travel reimbursement and honoraria for grand rounds presentations in Madisonville, KY. J. Halper and J. Hosey report no disclosures relevant to the manuscript. D. Jones has received personal compensation for consulting from Biogen and Genzyme; has received honoraria from the Consortium of Multiple Sclerosis Centers (CMSC), the Multiple Sclerosis Association of America (MSAA), and the Pharmacy Quality Alliance; has received institutional research support from Biogen and the National MS Society (NMSS); has received salary support from the CMSC; and has received travel reimbursement from Biogen and Genzyme and from the AAN, Can Do MS, the CMSC, and the MSAA. R. Lisak served as the President of the CMSC and serves as a member of the Board of the DMC Foundation; has served on scientific advisory boards for Mallinckrodt, Syntimmune, Celegene, and Alexion; serves as chair of the adjudication committee of a clinical trial (PAREXEL); has received funding for travel from the CMSC, the GBS/CIDP Foundation International, the NMSS, and Syntimmune for travel to consultants meetings; has served as a journal editor for Clinical and Experimental Neuroimmunology and Clinical Neuropharmacology; has received publishing royalties from Willey for International Neurology, A Clinical Approach; has received honoraria from Mallinckrodt, Syntimmune, and Teva Pharmaceuticals, and from the consulting agencies AlphaSights, ClearView Healthcare Partners, GLC, and Insights Consulting; has served on a speakers bureau for Teva Pharmaceuticals for talks unrelated to pharmaceuticals; has received research support from Mallinckrodt for investigator-initiated wet bench studies, and from Acorda, Avanir, Biogen, Chugai, Genentech, MedImmune, Novartis, and Teva Pharmaceuticals for serving as a site investigator in multicenter trials; has given expert testimony, prepared an affidavit and acted as witness for Teva Pharmaceuticals; and has acted as an expert on a patent case for Acorda. Wayne State University has received financial compensation from the NMSS for his salary as principle investigator for a research grant. R.A. Marrie receives research grants from nonprofit organizations, including Canadian Institutes of Health Research (CIHR), the CMSC, Crohn's and Colitis Canada, the NMSS, the Multiple Sclerosis Society of Canada, the Multiple Sclerosis Scientific Research Foundation, and Research Manitoba; and serves on the editorial board of Neurology. D. Pelletier has served on scientific advisory boards for Biogen, EMD Serono, Genzyme/Sanofi Aventis, Hoffman LaRoche, and Novartis; has received research support for Biogen, Genzyme, Hoffman LaRoche, and the National Institute of Neurologic Disorders and Stroke of the NIH; and has received honoraria for providing consulting services at scientific advisory board meetings from Biogen, EMD Serono, Genzyme/Sanofi Aventis, Hoffman LaRoche, and Novartis. S. Potrebic received an honorarium from CDI Quality Institute PLE for participation in a headache appropriate-use criteria panel for imaging; and receives travel reimbursement from the AAN for attending AAN Residency In-Service Training Examination Work Group meetings, AAN Axon Registry Committee meetings, AAN Guideline Development, Dissemination, and Implementation Subcommittee meetings, and the Guidelines International Network North America Evidence-based Guidelines Affecting Policy, Practice, and Stakeholders (E-GAPPS) conference. R. Sommers, C. Sitcov, and J. Stachowiak report no disclosures relevant to the manuscript. T. Getchius is a former AAN employee and reports no relevant disclosures. S. Merillat reports no disclosures relevant to the manuscript. T. Pringsheim has received research support from the CIHR and Shire Canada Inc. Go to Neurology.org/N for full disclosures.

\section{Disclaimer}

Clinical practice guidelines, practice advisories, systematic reviews, and other guidance published by the American Academy of Neurology and its affiliates are assessments of current scientific and clinical information provided as an educational service. The information (1) should not be considered inclusive of all proper treatments, methods of care, or as a statement of the standard of care; (2) is not continually updated and may not reflect the most recent evidence (new evidence may emerge between the time information is developed and when it is published or read); (3) addresses only the question(s) specifically identified; (4) does not mandate any particular course of medical care; and (5) is not intended to substitute for the independent professional judgment of the treating provider, as the information does not account for individual variation among people with MS. In all cases, the selected course of action should be considered by the treating 
provider in the context of treating the individual patient. Use of the information is voluntary. AAN provides this information on an "as is" basis, and makes no warranty, expressed or implied, regarding the information. AAN specifically disclaims any warranties of merchantability or fitness for a particular use or purpose. AAN assumes no responsibility for any injury or damage to persons or property arising out of or related to any use of this information or for any errors or omissions.

\section{Conflict of interest statement}

The American Academy of Neurology (AAN) is committed to producing independent, critical, and truthful clinical practice guidelines (CPGs). Significant efforts are made to minimize the potential for conflicts of interest to influence the recommendations of this CPG. To the extent possible, the AAN keeps separate those who have a financial stake in the success or failure of the products appraised in the CPGs and the developers of the guidelines. Conflict of interest forms were obtained from all authors and reviewed by an oversight committee prior to project initiation. AAN limits the participation of authors with substantial conflicts of interest. The AAN forbids commercial participation in, or funding of, guideline projects. Drafts of the guideline have been reviewed by at least 3 AAN committees, a network of neurologists, Neurology ${ }^{\circledR}$ peer reviewers, and representatives from related fields. The AAN Guideline Author Conflict of Interest Policy can be viewed at aan.com. For complete information on this process, access the 2011 AAN process manual, as amended. ${ }^{4}$

Received July 12, 2017. Accepted in final form February 15, 2018.

\section{References}

1. Rae-Grant A, Day GS, Marrie RA, et al; for the Guideline Development, Dissemination, and Implementation Subcommittee of the American Academy of Neurology. Practice guideline recommendations summary: disease-modifying therapies for adults with multiple sclerosis: report of the Guideline Development, Dissemination, and Implementation Subcommittee of the American Academy of Neurology. Neurology 2018;90:777-788.

2. Goodin DS, Frohman EM, Garmany GP, et al; on behalf of the American Academy of Neurology and the MS Council for Clinical Practice Guidelines. Disease-modifying therapies in multiple sclerosis: subcommittee of the American Academy of Neurology and the MS Council for Clinical Practice Guidelines: report of the Therapeutics and Technology Assessment Subcommittee of the American Academy of Neurology and the MS Council for Clinical Practice Guidelines. Neurology 2002;58:169-178.

3. Browne P, Chandraratna D, Angood C, et al. Atlas of Multiple Sclerosis 2013: a growing global problem with widespread inequity. Neurology 2014;83:1022-1024.

4. American Academy of Neurology. Clinical Practice Guideline Process Manual, 2011 ed. [online]. St. Paul: The American Academy of Neurology; 2011. Available at: aan. com/policy-and-guidelines/guidelines/about-guidelines2/. Accessed March 12, 2016.

5. Institute of Medicine; Eden J, Levit L, Berg A, Morton S, editors. Committee on Standards for Systematic Reviews of Comparative Effectiveness Research. Washington, DC: National Academies Press; 2011.

6. Institute of Medicine, Committee on Standards for Developing Trustworthy Clinical Practice Guidelines. Clinical Practice Guidelines We Can Trust. Washington, DC: National Academies Press; 2011.

7. Shea BJ, Grimshaw JM, Wells GA, et al. Development of AMSTAR: a measurement tool to assess the methodological quality of systematic reviews. BMC Med Res Methodol 2007;7:10

8. Guyatt GH, Oxman AD, Schunemann HJ, Tugwell P, Knottnerus A. GRADE guidelines: a new series of articles in the Journal of Clinical Epidemiology. J Clin Epidemiol 2011;64:380-382.

8a. Biogen and AbbVie announce the voluntary worldwide withdrawal of marketing authorizations for ZINBRYTA ${ }^{\star}$ (daclizumab) for relapsing multiple sclerosis [press release]. Available at: http://media.biogen.com/press-release/autoimmune-diseases/ biogen $\% \mathrm{C} 2 \% \mathrm{~A} 0$ and-abbvie-announce $\% \mathrm{C} 2 \% \mathrm{~A} 0$-voluntary\%C2\%A0worldwide-with drawal-marketi. Issued March 2, 2018. Accessed March 5, 2018.

9. Kappos L, Radue EW, O'Connor P, et al. A placebo-controlled trial of oral fingolimod in relapsing multiple sclerosis. N Engl J Med 2010;362:387-401.

10. Calabresi P, Radue EW, Goodin D, et al. Safety and efficacy of fingolimod in patients with relapsing-remitting multiple sclerosis (FREEDOMS II): a double-blind, randomised, placebo-controlled, phase 3 trial. Lancet Neurol 2014;13:545-556.

11. PRISMS (Prevention of Relapses and Disability by Interferon Beta-la Subcutaneously in Multiple Sclerosis) Study Group. Randomised double-blind placebo-controlled study of interferon beta-1a in relapsing/remitting multiple sclerosis. Lancet 1998;352: 1498-1504.

12. Polman C, O'Connor PW, Havdrova E, et al. A randomized, placebo-controlled trial of natalizumab for relapsing multiple sclerosis. N Engl J Med 2006;354:899-910.

13. Hauser SL, Bar-Or A, Comi G, et al; for the OPERA I and OPERA II Clinical Investigators. Ocrelizumab versus interferon beta-1a in relapsing multiple sclerosis. N Engl J Med 2017;376:221-234.

14. Giovannoni G, Comi G, Cook S, et al; on behalf of the CLARITY Study Group. A placebo-controlled trial of oral cladribine for relapsing multiple sclerosis. $\mathrm{N}$ Engl J Med 2010;362:416-426.

15. Cohen J, Coles AJ, Arnold DL, et al; CARE-MS I Investigators. Alemtuzumab versus interferon beta la as first-line treatment for patients with relapsing-remitting multiple sclerosis: a randomised controlled phase 3 trial. Lancet 2012;380:1819-1828.

16. Cohen J, Barkhof F, Comi G, et al; on behalf of the TRANSFORMS Study Group. Oral fingolimod or intramuscular interferon for relapsing multiple sclerosis. $\mathrm{N}$ Engl J Med 2010;362:402-415.

17. Panitch H, Goodin DS, Francis G, et al; or the University of British Columbia MS/ MRI Research Group. Randomized, comparative study of interferon beta-1a treatment regimens in MS the EVIDENCE Trial. Neurology 2002;59:1496-1506.

18. Fox R, Miller DH, Phillips JT, et al; on behalf of the CONFIRM Study Investigators. Placebo-controlled phase 3 study of oral BG-12 or glatiramer in multiple sclerosis. N Engl J Med 2012;367:1087-1097.

19. Massacesi L, Tramacere I, Amoroso S, et al. Azathioprine versus beta interferons for relapsing-remitting multiple sclerosis: a multicentre randomized non-inferiority trial. PLoS One 2014;9:e113371.

20. Gold R, Giovannoni G, Selmaj K, et al; on behalf of the SELECT Study Investigators. Daclizumab high-yield process in relapsing-remitting multiple sclerosis (SELECT): a randomised, double-blind, placebo-controlled trial. Lancet 2013; 381:2167-2175.

21. Gold R, Kappos L, Arnold DL, et al; on behalf of the DEFINE Study Investigators. Placebo-controlled phase 3 study of oral BG-12 for relapsing multiple sclerosis. N Engl J Med 2012;367:1098-1107.

22. Vollmer T, Sorensen PS, Selmaj K, et al; on behalf of the BRAVO Study Group. A randomized placebo-controlled phase III trial of oral laquinimod for multiple sclerosis. J Neurol 2014;261:773-783.

23. Millefiorini E, Gasperini C, Pozzilli C, et al. Randomized placebo-controlled trial of mitoxantrone in relapsing-remitting multiple sclerosis: 24-month clinical and MRI outcome. J Neurol 1997;244:153-159.

24. Calabresi P, Kieseier BC, Arnold DL, et al; for the ADVANCE Study Investigators. Pegylated interferon beta-1a for relapsing-remitting multiple sclerosis (ADVANCE) a randomised, phase 3, double-blind study. Lancet Neurol 2014;13:657-665.

25. Hauser SL, Waubant E, Arnold DL, et al; for the HERMES Trial Group. B-cell depletion with rituximab in relapsing-remitting multiple sclerosis. N Engl J Med 2008; 358:676-688.

26. O'Connor P, Wolinsky JS, Confavreux C, et al; for the TEMSO Trial Group. Randomized trial of oral teriflunomide for relapsing multiple sclerosis. N Engl J Med 2011;365:1293-1303.

27. Kappos L, Wiendl H, Selmaj K, et al. Daclizumab HYP versus interferon beta-1a in relapsing multiple sclerosis. N Engl J Med 2015;373:1418-1428.

28. Frohman EM, Cutter G, Remington G, et al. A randomized, blinded, parallel-group, pilot trial of mycophenolate mofetil (CellCept) compared with interferon beta-1a (Avonex) in patients with relapsing-remitting multiple sclerosis. Ther Adv Neurol Disord 2010;3:15-28.

29. Coles A, Twyman CL, Arnold DL, et al; the CARE-MS II Investigators. Alemtuzumab for patients with relapsing multiple sclerosis after disease-modifying therapy: a randomised controlled phase 3 trial. Lancet 2012;80:1829-1839.

30. Zivadinov R, Rudick RA, De Masi R, et al. Effects of IV methylprednisolone on brain atrophy in relapsing-remitting MS. Neurology 2001;57:1239-1247.

31. Remington GM, Treadaway K, Frohman T, et al. A one-year prospective, randomized, placebo-controlled, quadruple-blinded, phase II safety pilot trial of combination therapy with interferon beta-1a and mycophenolate mofetil in early relapsing-remitting multiple sclerosis (TIME MS). Ther Adv Neurol Disord 2010; 3:3-13.

32. Jacobs L, Cookfair DL, Rudick RA, et al. Intramuscular interferon beta-1a for disease progression in relapsing multiple sclerosis. Ann Neurol 1996;39:285-294.

33. Confavreux C, O'Connor P, Comi G, et al; for the TOWER Trial Group. Oral teriflunomide for patients with relapsing multiple sclerosis (TOWER): a randomised, double-blind, placebo-controlled, phase 3 trial. Lancet Neurol 2014;13:247-256.

34. Johnson KP, Brooks BR, Cohen JA, et al. Copolymer 1 reduces relapse rate and improves disability in relapsing-remitting multiple sclerosis: results of a phase III multicenter, double-blind placebo-controlled trial: Copolymer 1 Multiple Sclerosis Study Group. Neurology 1995;45:1268-1276. 
35. Bornstein MB, Miller A, Slagle S, et al. A pilot trial of COP 1 in exacerbating-remitting multiple sclerosis. N Engl J Med 1987;317:408-414.

36. Ravnborg M, Sorensen PS, Andersson M, et al. Methylprednisolone in combination with interferon beta-1a for relapsing-remitting multiple sclerosis (MECOMBIN study): a multicentre, double-blind, randomized, placebo-controlled, parallel-group study. Lancet Neurol 2010;9:672-680.

37. Lublin FD, Cofield SS, Cutter GR, et al; on behalf of the CombiRx Investigators. Randomized study combining interferon and glatiramer acetate in multiple sclerosis. Ann Neurol 2013;73:327-340
38. Ellison G, Myers LW, Mickey MR, et al. A placebo-controlled, randomized, doublemasked, variable dosage, clinical trial of azathioprine with and without methylprednisolone in multiple sclerosis. Neurology 1989;39:1018-1026.

39. Fazekas F, Deisenhammer F, Stasser-Fuchs S, Nahler G, Mamoli B. Randomised placebo-controlled trial of monthly intravenous immunoglobulin therapy in relapsingremitting multiple sclerosis: Austrian Immunoglobulin in Multiple Sclerosis Study Group. Lancet 1997;349:598-593.

40. Achiron A, Gabbay U, Gilad R, et al. Intravenous immunoglobulin treatment in multiple sclerosis, effect on relapses. Neurology 1998;50:398-402.

\section{Neurology ${ }^{\circledast}$ Online CME Program}

Earn CME while reading Neurology. This program is available only to online Neurology subscribers. Read the articles marked CME, go to Neurology.org, and click on CME. This will provide all of the information necessary to get started. The American Academy of Neurology (AAN) is accredited by the Accreditation Council for Continuing Medical Education (ACCME) to sponsor continuing medical education for physicians. Neurology is planned and produced in accordance with the ACCME Essentials. For more information, contact AAN Member Services at 800-879-1960.

\section{Neurology.org/N Offers Important Information to Patients and Their Families}

The Neurology ${ }^{\circledR}$ Patient Page provides:

- A critical review of ground-breaking discoveries in neurologic research that are written especially for patients and their families

- Up-to-date patient information about many neurologic diseases

- Links to additional information resources for neurologic patients

All Neurology Patient Page articles can be easily downloaded and printed, and may be reproduced to distribute for educational purposes. Click on the 'Patients' link on the home page (Neurology.org/N) for a complete index of Patient Pages.

\section{Visit the Neurology ${ }^{\circledR}$ Website at Neurology.org/N}

- More article-based content on home pages

- Streamlined menus and navigation

- Enhanced blog sections for specialty areas

- Same experience on desktop, tablet, and mobile devices

- Audio summaries of current issues

- Improved article reading experience; links more evident (pdf, analytics, social media)

- Neurology ${ }^{\circledR}$ Clinical Practice initiative "Practice Current" global surveys will be accessible across sites

f Find Neurology ${ }^{\circledR}$ on Facebook: http://tinyurl.com/neurologyfan

Follow Neurology ${ }^{\circledR}$ on Twitter: https://twitter.com/GreenJournal 


\section{Neurology}

Comprehensive systematic review summary: Disease-modifying therapies for adults with multiple sclerosis: Report of the Guideline Development, Dissemination, and Implementation Subcommittee of the American Academy of Neurology Alexander Rae-Grant, Gregory S. Day, Ruth Ann Marrie, et al. Neurology 2018;90;789-800

DOI 10.1212/WNL.0000000000005345

This information is current as of April 23, 2018

Updated Information \& Services

Supplementary Material

References

Citations

Subspecialty Collections

Errata

Permissions \& Licensing

Reprints including high resolution figures, can be found at: http://n.neurology.org/content/90/17/789.full

Supplementary material can be found at: http://n.neurology.org/content/suppl/2018/04/23/90.17.789.DC1

This article cites 37 articles, 8 of which you can access for free at: http://n.neurology.org/content/90/17/789.full\#ref-list-1

This article has been cited by 8 HighWire-hosted articles: http://n.neurology.org/content/90/17/789.full\#\#otherarticles

This article, along with others on similar topics, appears in the following collection(s):

Multiple sclerosis

http://n.neurology.org/cgi/collection/multiple_sclerosis

An erratum has been published regarding this article. Please see next page or:

/content/93/17/769.full.pdf

Information about reproducing this article in parts (figures,tables) or in its entirety can be found online at:

http://www.neurology.org/about/about_the_journal\#permissions

Information about ordering reprints can be found online:

http://n.neurology.org/subscribers/advertise

Neurology ${ }^{\circledR}$ is the official journal of the American Academy of Neurology. Published continuously since 1951, it is now a weekly with 48 issues per year. Copyright @ 2018 American Academy of Neurology. All rights reserved. Print ISSN: 0028-3878. Online ISSN: 1526-632X.

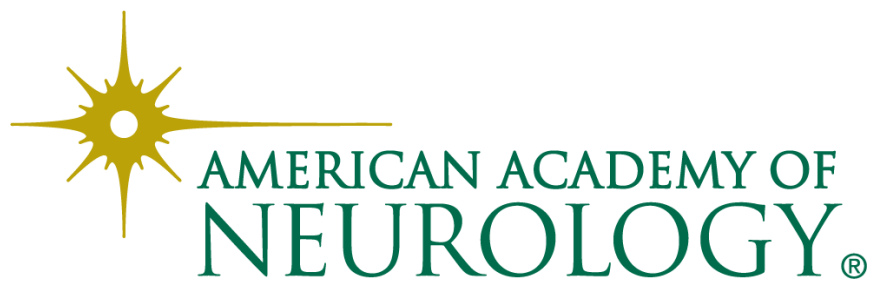




\title{
Disputes \& Debates: Editors' Choice
}

Steven Galetta, MD, FAAN, Section Editor

\begin{abstract}
Editors' note: Comprehensive systematic review summary: Diseasemodifying therapies for adults with multiple sclerosis: Report of the Guideline Development, Dissemination, and Implementation Subcommittee of the American Academy of Neurology

In the special article "Comprehensive systematic review summary: Disease-modifying therapies for adults with multiple sclerosis," Rae-Grant et al. reported the findings of the Guideline Development, Dissemination, and Implementation Subcommittee of the American Academy of Neurology based on reviewing the evidence on starting, switching, and stopping disease-modifying therapies for clinically isolated syndrome, relapsingremitting MS, and progressive forms of MS. In response, Dr. Tran, on behalf of Genentech, argues that the report did not make it clear that data on annualized relapse rate reduction and relative risk of in-study disability progression for ocrelizumab (presented along with other therapies in figures 1 and 3 ) were from direct comparisons with subcutaneous interferon- $\beta$-1a $44 \mu \mathrm{g} 3$ times weekly in 2 phase 3 randomized, double-blind, double-dummy trials. In response, Dr. Rae-Grant agrees that this information should have been included, but notes that statements in the text of the summary and in a key accompanying table acknowledged the superior efficacy of ocrelizumab compared with interferon- $\beta$-1a 3 times weekly. Dr. Rae-Grant also notes that data on subgroup analysis of treatment of highly active MS with ocrelizumab were not available at the time of publication of the systematic review.
\end{abstract}

Aravind Ganesh, MD, DPhil, and Steven Galetta, MD

Neurology ${ }^{\circledR}$ 2019;93:764. doi:10.1212/WNL.0000000000008365

\section{Reader response: Comprehensive systematic review summary: Disease-modifying therapies for adults with multiple sclerosis: Report of the Guideline Development, Dissemination, and Implementation Subcommittee of the American Academy of Neurology}

Katherine R. Tran (San Francisco)

Neurology ${ }^{\circledR}$ 2019;93:764-765. doi:10.1212/WNL.0000000000008366

Genentech recognizes that high-quality and trustworthy guidelines, such as those published by the American Academy of Neurology, are important both for providers to optimize patient care and for payers to manage appropriate utilization of multiple sclerosis (MS) treatments. We appreciate the opportunity to provide the following corrections to inform accurate recommendations for health care decision makers.

The Comprehensive Systematic Review Summary omits key information regarding ocrelizumab in figures 1 and 3. ${ }^{1}$ Figure 1 lists disease-modifying therapies (DMTs) by annualized relapse rate (ARR) reductions from highest to lowest; figure 3 lists DMTs by relative risk of in-study disability progression at 2 years. The figures do not include a footnote indicating that the ARR and disability progression for ocrelizumab are relative to subcutaneous interferon- $\beta$ - $1 \mathrm{a} 44 \mu \mathrm{g} 3$ times weekly, although there is such a note included for alemtuzumab. 
The efficacy and safety of ocrelizumab compared with subcutaneous interferon- $\beta$-1a $44 \mu \mathrm{gg}$ times weekly in RMS was evaluated in 2 identical, phase 3, randomized (1:1), double-blind, double-dummy, head-to-head comparative trials. ${ }^{2,3}$ Readers may infer indirect treatment comparisons using these figures, and the omission of this fundamental detail misrepresents the relative efficacy of MS DMTs.

1. Rae-Grant A, Day GS, Marrie RA, et al. Comprehensive systematic review summary: disease-modifying therapies for adults with multiple sclerosis: Report of the guideline development, dissemination, and implementation subcommittee of the American Academy of Neurology. Neurology 2018;90:789-800.

2. Hauser SL, Bar-Or A, Comi G, et al. Ocrelizumab versus interferon beta-1a in relapsing multiple sclerosis. N Engl J Med 2017;376:221-234.

3. Genentech, Inc Highlights of prescribing information: ocrevus (ocrelizumab) injection, for intravenous use: full prescribing information. Available at: gene.com/download/pdf/ocrevus_prescribing.pdf. Accessed: December 12, 2018.

Copyright @ 2019 American Academy of Neurology

\section{Author response: Comprehensive systematic review summary: Disease-modifying therapies for adults with multiple sclerosis: Report of the Guideline Development, Dissemination, and Implementation Subcommittee of the American Academy of Neurology}

Alex D. Rae-Grant (Cleveland)

Neurology ${ }^{\circledR}$ 2019;93:765. doi:10.1212/WNL.0000000000008376

I thank Dr. Tran for the comment on our comprehensive systematic review summary for the American Academy of Neurology guideline on disease-modifying therapy for adults with multiple sclerosis (MS). ${ }^{1}$

In regard to figures 1 and $3,{ }^{1}$ Dr. Tran correctly points out that critical information related to the ocrelizumab findings should have been included in each figure to indicate that the ocrelizumab findings are in comparison with interferon- $\beta$-1a (IFN- $\beta$-1a). We regret missing this in our proofing of this set of long and complex articles.

The text of the summary, a key accompanying table, and the full-text guideline document reflect the active comparator using IFN- $\beta$-1a subcutaneous 3 times per week. ${ }^{1}$ The following language was used for conclusions about ocrelizumab: "Ocrelizumab ${ }^{13}$ is more effective than IFN- $\beta$-1a subcutaneous 3 times per week ... (high confidence);" "Ocrelizumab ${ }^{13}$ is more effective than IFN- $\beta$-1a 44 g subcutaneous 3 times weekly... (high confidence).”

In addition, a key table of efficacy for reducing the annualized relapse rate for relapsing MS documented the active comparator status in the summary ${ }^{1}$ as follows: "Ocrelizumab more effective than IFN- $\beta$-1a subcutaneous 3 times per wk."

This information should have been included in the published article, and we will notify the Neurology journal of this error as quickly as feasible.

We further appreciate your comments about subgroup analysis of treatment of highly active MS with ocrelizumab. Unfortunately, these data were not published when we completed our systematic review.

Medicine is a constantly evolving process; we noted this in our summary. How payers use guidelines to make decisions about access to care is beyond the scope and control of guideline development.

1. Rae-Grant A, Day GS, Marrie RA, et al. Comprehensive systematic review summary: disease-modifying therapies for adults with multiple sclerosis: Report of the Guideline Development, Dissemination, and Implementation Subcommittee of the American Academy of Neurology. Neurology 2018;90:789-800.

Copyright (c) 2019 American Academy of Neurology 


\section{Editors' note: High prevalence of neutralizing antibodies after long- term botulinum neurotoxin therapy}

In the article "High prevalence of neutralizing antibodies after long-term botulinum neurotoxin therapy," Albrecht et al. investigated the prevalence of neutralizing antibodies (NAbs) against botulinum neurotoxin type A (BoNT/A) in a monocentric, observational cross-sectional study of 596 outpatients treated with BoNT/A over a mean of 5.3 years for different indications and found that $13.9 \%$ had measurable NAbs. The probability of developing NAbs increased with the single and cumulative dose of treatment and was associated with the BoNT/A formulation used, leading the authors to recommend avoiding booster injections and reducing the individual injected doses. In response, Dr. Jankovic notes that the authors did not mention other studies that showed a much lower frequency of NAbs, although after shorter periods of observation, and indicates that no data were provided regarding any correlation between the presence of NAbs and clinical response. In this regard, Dr. Jankovic notes that none of the patients in a previous study with blocking antibodies identified by the mouse protection assay (MPA) had any clinical response, suggesting that the MPA may be more clinically meaningful. In their reply, Albrecht et al. postulate that lower rates of NAbs in previous studies may relate to lower sensitivity of the MPA, lower BoNT doses used, and substantially shorter duration of treatment. In contrast to Dr. Jankovic's findings, they report that all their patients with NAbs opted to continue treatment and reported ongoing subjective benefit. Both the authors and Dr. Jankovic agree on the need for novel assays with higher sensitivity and specificity that are (ideally) not animal based. In another response, Mulroy et al. caution that the authors' conclusions may mislead readers into thinking that long-term treatment with frequent or repeated BoNT injections can result in clinical treatment failure. Like Dr. Jankovic, they too highlight the absence of data on clinical effectiveness in this study and note that NAb serostatus did not always correlate with clinical response in previous studies. They also seek to clarify the authors' disclosures, given that the study was funded by Merz Pharmaceuticals, which manufacturers one of the BoNT formulations studied. Replying to these comments, Albrecht et al. argue that there is consensus that the induction of NAbs should be avoided, as they are associated with reduced treatment response in several studies. They acknowledge that they do not have information about NAb induction with treatment intervals shorter than 10 weeks in their study, note the difficulty of comparing treatment efficacy across different indications, and concede that efficacy data were not available for all patients. They also state that pharmaceutical funding had no influence on the interpretation or analysis of their data. This correspondence highlights enduring uncertainty in the field regarding the clinical implications of NAbs as detected by existing animal-based assays.

\section{Reader response: High prevalence of neutralizing antibodies after long-term botulinum neurotoxin therapy}

Joseph Jankovic (Houston)

Neurology ${ }^{\circledR}$ 2019;93:766-767. doi:10.1212/WNL.0000000000008379

In the article by Albrecht et al., ${ }^{1}$ the authors reported nearly $14 \%$ prevalence of neutralizing antibodies, determined by mouse hemidiaphragm assay (MHDA), among 596 patients treated with botulinum neurotoxin type A (BoNT/A), mostly with abo-BoNT/A $(\mathrm{n}=324)$. They cited similar 
prevalence of neutralizing antibodies based on their own study, ${ }^{2}$ but they failed to mention other studies showing much lower frequency of such antibodies, albeit after a shorter observation period. For example, in a prospective study of 326 patients with cervical dystonia treated with BoNT/A, only $1.2 \%$ tested positive for antibodies detected by the mouse protection assay (MPA). ${ }^{3}$ Albrecht et al. ${ }^{1}$ provided no data on the correlation between the presence of antibodies detected by MHDA and clinical response, although they stated that their patients were "still responding."

In contrast, none of our patients with positive titers for blocking antibodies tested by MPA had any clinical response, indicative of true immunoresistance. ${ }^{4}$ Therefore, the latter assay is more clinically meaningful as it correlates well with clinical response, which may explain the differences in the reports of secondary unresponsiveness among various studies using different assays and BoNT products. ${ }^{5}$ More sensitive and specific assays that are not animal based are needed to monitor the emergence of blocking antibodies, particularly in patients treated chronically with high doses of BoNT.

1. Albrecht P, Jansen A, Lee JI, et al. High prevalence of neutralizing antibodies after long-term botulinum neurotoxin therapy. Neurology 2019;92:e48-e54.

2. Hefter H, Rosenthal D, Moll M. High botulinum toxin-neutralizing antibody prevalence under long-term cervical dystonia treatment. Mov Disord Clin Pract 2016;3:500-506.

3. Brin MF, Comella CL, Jankovic J, et al. Long-term treatment with botulinum toxin type A in cervical dystonia has low immunogenicity by mouse protection assay. Mov Disord 2008;23:1353-1360.

4. Hanna PA, Jankovic J. Mouse bioassay versus Western blot assay for botulinum toxin antibodies: correlation with clinical response. Neurology 1998;50:1624-1629.

5. Bellows S, Jankovic J. Immunogenicity Associated with Botulinum Toxin Treatment. Toxins (Basel). 2019:Aug 26;11(9).

Copyright (c) 2019 American Academy of Neurology

\section{Author response: High prevalence of neutralizing antibodies after long-term botulinum neurotoxin therapy}

Philipp Albrecht (Düsseldorf, Germany), Alexander Jansen (Düsseldorf, Germany),

John-Ih Lee (Düsseldorf, Germany), Marius Ringelstein (Düsseldorf, Germany),

Orhan Aktas (Düsseldorf, Germany), Hans-Peter Hartung (Düsseldorf, Germany),

Hans Bigalke (Hannover, Germany), and Harald Hefter (Düsseldorf, Germany)

Neurology ${ }^{\circledR}$ 2019;93:767-768. doi:10.1212/WNL.0000000000008378

We thank Dr. Jankovic for his valuable comments on our article. ${ }^{1}$ The study by Brin et al., ${ }^{2}$ which, along with similar studies, is analyzed in a review referenced in our article, ${ }^{3}$ reported lower rates of neutralizing antibodies (NAbs) (1.4\% at a mean treatment duration of 2.5 years and maximum duration of 4 years) in cervical dystonia. Reasons may be a lower sensitivity of the mouse protection assay (MPA) compared with our mouse hemidiaphragm test, the lower doses applied, and the fact that the treatment duration was substantially shorter than in our study (mean 5.3 years and maximum 23 years). We completely agree that the clinical relevance of the observed NAbs should be investigated by assessing the clinical response. These investigations are underway and will be the subject of a following publication. However, we can already state that we do not share Dr. Jankovic's impression that all patients with detectable NAbs display complete unresponsiveness. All our patients were on continued treatment by choice and reported at least some subjective benefit of therapy. ${ }^{1}$ This is in line with previous studies using the MPA that also reported responsiveness in some patients despite positive NAbs. ${ }^{2,4}$ We agree that novel, ideally not animal-based, assays with high sensitivity and specificity should be established and validated.

1. Albrecht P, Jansen A, Lee JI, et al. High prevalence of neutralizing antibodies after long-term botulinum neurotoxin therapy. Neurology 2019;92:e48-e54. 
2. Brin MF, Comella CL, Jankovic J, et al. Long-term treatment with botulinum toxin type A in cervical dystonia has low immunogenicity by mouse protection assay. Mov Disord 2008;23:1353-1360.

3. Naumann M, Boo LM, Ackerman AH, Gallagher CJ. Immunogenicity of botulinum toxins. J Neural Transm (Vienna) 2013;120: 275-290.

4. Naumann M, Carruthers A, Carruthers J, et al. Meta-analysis of neutralizing antibody conversion with onabotulinumtoxinA (BOTOX $\left.{ }^{\circ}\right)$ across multiple indications. Mov Disord 2010;25:2211-2218.

Copyright (c) 2019 American Academy of Neurology

\section{Reader response: High prevalence of neutralizing antibodies after long-term botulinum neurotoxin therapy}

Eoin Mulroy (London), Bettina Balint (Heidelberg, Germany), and Amit Batla (Luton, UK) Neurology ${ }^{\circledR}$ 2019;93:768. doi:10.1212/WNL.0000000000008380

We read with interest the article by Albrecht et al., ${ }^{1}$ which demonstrated that $14 \%$ of 596 patients treated with various botulinum toxin (BoNT) preparations over 2-5 years developed neutralizing antibodies (Nabs). Although the study clearly focuses on the presence of Nabs and not on the clinical effect, the conclusions by Albrecht et al. ${ }^{1}$ that " $\ldots$ avoiding booster injections and providing short intervals between injections... may diminish the risk of NAb induction..." and that " $\ldots$ the dose per injection session should be kept as low as possible to avoid clinically relevant immunization..." could mislead readers into believing that long-term treatment with frequent or repeated BoNT injections can result in clinical treatment failure.

The authors stated that "... patients were still responding (at least partially)...," but do not include data on clinical effectiveness. Most prior studies in this area have done so, as this greatly impacts on patient management. ${ }^{2}$ It would be useful to know whether these data were not collected or have been omitted from publication intentionally. As previously demonstrated, $\mathrm{Nab}$ serostatus does not necessarily correlate with clinical response to repeated injections. ${ }^{2,3}$

Last, the authors reported no disclosures related to the study, ${ }^{1}$ yet the study was funded by a pharmaceutical company that manufactures one of the BoNTs included in the study. This needs clarification.

1. Albrecht P, Jansen A, Lee JI, et al. High prevalence of neutralizing antibodies after long-term botulinum neurotoxin therapy. Neurology 2019;92:e48-e54

2. Fabbri M, Leodori G, Fernandes RM, et al. Neutralizing antibody and botulinum toxin therapy: a systematic review and meta-analysis. Neurotox Res 2016;29:105-117.

3. Brin MF, Comella CL, Jankovic J, Lai F, Naumann M. Long-term treatment with botulinum toxin type A in cervical dystonia has low immunogenicity by mouse protection assay. Mov Disord 2008;23:1353-1360.

Copyright (c) 2019 American Academy of Neurology

\section{Author response: High prevalence of neutralizing antibodies after long-term botulinum neurotoxin therapy}

Philipp Albrecht (Düsseldorf, Germany), Alexander Jansen (Düsseldorf, Germany), John-lh Lee (Düsseldorf, Germany), Orhan Aktas (Düsseldorf, Germany), Hans Bigalke (Hannover, Germany), Hans-Peter Hartung (Düsseldorf, Germany), and Harald Hefter (Düsseldorf, Germany) Neurology ${ }^{\circledR}$ 2019;93:768-769. doi:10.1212/WNL.0000000000008381

We thank Mulroy et al. for their comment on our article. ${ }^{1}$ The association of neutralizing antibodies (NABs) against botulinum neurotoxin $\mathrm{A}$ and a reduced treatment response has been reported in several publications. ${ }^{2,3}$ It is, therefore, consensus that the induction of NABs should be avoided if possible. Given the constant treatment intervals $>10$ weeks in our study, ${ }^{1}$ we do 
not have information about $\mathrm{NAB}$ induction with shorter treatment intervals. With these regimens, an impact was reported in previous studies. ${ }^{4,5}$ Our investigation was directed to identify other factors relevant for the induction of NABs and the prevalence in a large sample of treatment responsive patients across different indications. As comparing treatment efficacy across different indications is challenging and efficacy data was not available for all patients, we chose to not focus on treatment response.

Funding by Merz Pharmaceuticals was transparently reported at the bottom of the manuscript and all unrelated disclosures are listed on the journal webpage. As this funding had no influence on the interpretation or analysis of the data, it was not additionally listed as a relevant disclosure.

1. Albrecht P, Jansen A, Lee JI, et al. High prevalence of neutralizing antibodies after long-term botulinum neurotoxin therapy. Neurology 2019;92:e48-e54.

2. Greene P, Fahn S, Diamond B. Development of resistance to botulinum toxin type A in patients with torticollis. Mov Disord 1994;9: 213-217.

3. Göschel H, Wohlfarth K, Frevert J, Dengler R, Bigalke H. Botulinum A toxin therapy: neutralizing and nonneutralizing antibodies-therapeutic consequences. Exp Neurol 1997;147:96-102.

4. Naumann M, Boo LM, Ackerman AH, Gallagher CJ. Immunogenicity of botulinum toxins. J Neural Transm (Vienna) 2013;120: $275-290$.

5. Lange $\mathrm{O}$, Bigalke $\mathrm{H}$, Dengler R, et al. Neutralizing antibodies and secondary therapy failure after treatment with botulinum toxin type A much ado about nothing? Clin Neuropharmacol 2009;32:213-218.

Copyright @ 2019 American Academy of Neurology

CORRECTION

Comprehensive systematic review summary: Disease-modifying therapies for adults with multiple sclerosis: Report of the Guideline Development, Dissemination, and Implementation Subcommittee of the American Academy of Neurology

Neurology ${ }^{\circledR}$ 2019;93:769. doi:10.1212/WNL.0000000000008374

In the special article "Comprehensive systematic review summary: Disease-modifying therapies for adults with multiple sclerosis: Report of the Guideline Development, Dissemination, and Implementation Subcommittee of the American Academy of Neurology," by Rae-Grant et al., there are errors in figures 1 and 3. In figure 1, a superscript " $a$ " is missing from "Ocrelizumab" to indicate the comparator intervention (interferon- $\beta$-1a $44 \mu \mathrm{g} 3$ times per week subcutaneously); in figure 3, a superscript " $b$ " is missing from "Ocrelizumab," also to indicate the comparator intervention (interferon- $\beta$-1a). Additionally, in the table "Efficacy of disease modifying therapies (DMTs) for reducing the annualized relapse rate (ARR) and risk of relapse at 2 years," there should not be an entry for "very low" confidence for azathioprine under "Reduction of the ARR." The entry for very low confidence for azathioprine under "Reduction of risk of relapse at $2 \mathrm{y}$ " appears correctly. The authors regret the errors.

\section{Reference}

1. Rae-Grant A, Day GS, Marrie RA, et al. Comprehensive systematic review summary: Disease-modifying therapies for adults with multiple sclerosis: Report of the Guideline Development, Dissemination, and Implementation Subcommittee of the American Academy of Neurology. Neurology 2018;90:789-800. 